\title{
New Interview Method for Sketching the Dynamic Relational and Sexual History of Young Adults
}

\author{
Daphne van de Bongardt ${ }^{1} \cdot$ Mirthe Verbeek $^{1}$
}

Accepted: 5 November 2020 / Published online: 1 January 2021

(c) The Author(s) 2020

\begin{abstract}
Introduction Scientific literature and clinical practice still pay insufficient attention to the interconnectedness between love and sex. Especially youth would benefit in their sexual development from more attention (e.g., in parenting, education, sexual health services) for the complex relational context of sexual decisions and interactions.

Methods To gain more insight into young people's dynamically intertwined early experiences with romantic relationships and sexuality, a new semi-structured interview method was developed as part of a larger study on the interrelatedness of love and sex ("Lovely sex or sexy love?"). The newly developed Relational and Sexual History (RSH) interview consists of five steps and is visually supported by a relationship matrix to sketch how developments in relational and sexual aspects of early intimate relationships (from adolescence to young adulthood) are interrelated, and how youth learn cumulatively (across their relationships) about what they do and do not want in their intimate partnerships.

Results The RSH interview method was piloted in 2018 in a small-scale qualitative study with $N=16$ young adults ( 9 women, $7 \mathrm{men}$; $18-25$ years). This pilot study showed the method is suitable to assess the chronologic, dynamic, and intertwined relational and sexual histories of youth in a semi-structured manner.

Conclusions and Policy Implications The RSH interview method may advance scientific research on the linkages between love and sex and can be a valuable tool for clinical practice in sexology and relationship therapy (and increase cross-pollination between these clinical fields). The type of knowledge yielded by these interviews may profoundly impact policies for relational and sexual health promotion for youth.
\end{abstract}

Keywords Romantic relationships $\cdot$ Sexuality $\cdot$ Developmental history $\cdot$ Young adults $\cdot$ Semi-structured interview method

Historically, scientific research fields on young people's romantic relationships, on the one hand, and their sexuality, on the other hand, have developed relatively independently from one another (Impett, Muise, \& Peragine, 2014; Van de Bongardt, Yu, Deković, \& Meeus, 2015). This was a remarkable development, as romantic relationships are a typical context in which the sexual behaviors of most adolescents and young adults occur and develop (Boislard, Van de Bongardt, \& Blais, 2016; De Graaf, Van den Borne, Nikkelen, Twisk, \& Meijer, 2017). Over the past decade, various scientists have increasingly advocated the relevance of research on youth sexuality within romantic relationships (Giordano, Manning, \& Longmore

Daphne van de Bongardt

vandebongardt@essb.eur.nl

1 Department of Psychology, Education and Child Studies, Erasmus University Rotterdam, Rotterdam, Netherlands
2010; Impett et al., 2014; Van de Bongardt et al., 2015; Zimmer-Gembeck, Siebenbruner, \& Collins, 2004). Several studies have shown that romantic relationship experiences are related to young people's sexual behaviors. For instance, adolescents who initiated romantic relationships at an earlier age also reported more lifetime sexual partners by age 19 (Zimmer-Gembeck et al., 2004). But also teens' subjective experiences of their romantic relationship qualities (e.g., communication processes, power dynamics) have been shown as relevant for their sexual behavior choices (Giordano et al, 2010). Furthermore, concerning linkages between romantic relationship experiences and young people's sexual cognitions and emotions, studies have shown that adolescents who explored their own dating identity had healthier sexual attitudes (McElwain, Kerpelman, \& Pittman, 2015); that young people who had been in a committed romantic relationship tended to have higher selfesteem as a sexual partner (Maas \& Lefkowitz, 2015); that 
young adults in a committed, long-lasting relationship were more satisfied with their sex life (Pedersen \& Blekesaune, 2003); that kissing and desiring a romantic partner contributed positively to relationship satisfaction and commitment within romantic couples aged 14-21 years (Welsh, Haugen, Widman, Darling, \& Grello, 2005); and that young men and women who had intentional or planned first intercourse also experienced this as more loving (Smiler, Ward, Caruthers, \& Merriwether, 2005).

Notwithstanding the growing body of literature on the interlinkages between young people's romantic experiences and sexuality, currently, still much remains unknown on how characteristics of romantic relationships and partners are linked with sexual behaviors and experiences of youth throughout their relational and sexual developmental trajectories. How do young people develop their negotiation skills on the use of contraception within their subsequent romantic relationships? How do they experience and develop their skills to create sexual pleasure with different romantic partners? How do young people learn across their various partnerships about what they $d o$ and do not like when having sex? How do they reflect on their relational and sexual satisfaction across different intimate relationships, and how do these two aspects cross-pollinate one another? These are merely examples of the many questions that are still largely unanswered, but which are relevant for our understanding of relational, sexual, and general wellbeing of young people.

To gain more insight into the dynamic interrelations between early-life experiences with romantic relationships and sexuality of young people, a new semi-structured interview method was developed: the Relational and Sexual History (RSH) interview. This method was developed as part of a larger study on the interrelatedness of love and sex within young couples ("Lovely sex of sexy love?"; Van de Bongardt, 2018). The current paper serves as an introduction of this new interview method: It entails a description of the development of the methodology, an illustration on the type of information it generates, and concludes with a reflection on the applicability of this interview method within various scientific and clinical settings.

\section{Qualitative Life History Methods}

The newly developed RSH interview method fits within a tradition of various earlier (inter)national studies in which qualitative life history methods were used to collect data on the relational and sexual development of adolescents and young adults. More specifically, these methods have previously been applied to collect retrospective data, and analyze subjective experiences with developing intimacy and sexuality (Cense, 2015, 2014; Cense \& Ganzevoort, 2017; Giordano et al., 2010; Jones \& Furman, 2011; Lantagne \& Furman, 2017; Luke, Clark, \& Zulu, 2011; O'Sullivan, Cheng, Harris, \& Brooks-Gunn, 2007). The used methods mainly consisted of in-depth interviews that were-in varying degrees-characterized as open (Cense, 2014; Cense \& Ganzevoort, 2017; Giordano et al., 2010), semi-structured (Cense, 2015; Jones \& Furman, 2011; Lantagne \& Furman, 2017; Luke et al., 2011), or structured (O'Sullivan et al., 2007) interviews. All these forms of interviewing simulate a familiar daily conversation, which stimulates the interviewee to talk openly about her/his personal experiences and perspectives (Boeije, 2009; Kvale, 2007). One advantage of these interview formats is that it gives young people an opportunity to talk about their subjective ideas and experiences in their own style and words, and to elaborate on topics that are important and relevant to them personally. This way, the collected data are a better reflection of their personal and subjective experiences and perspectives within their own relational and sexual history. At the same time, they are goal-oriented interviews, with questions that need to be covered during the interview formulated beforehand (in a topic list).

In this line of research, various studies have utilized the semi-structured Romantic Interview (RI) method to collect descriptions of previous romantic relationships of adolescents and young adults (e.g., Jones \& Furman, 2011; Lantagne \& Furman, 2017). In the Toledo Adolescent Relationships Study (TARS), open-ended interviews were held with a subsample of the participants to collect relationship history narratives that provided qualitative data on relationship-sexuality connections from adolescents' own perspectives (Giordano et al., 2010). In the Netherlands, Cense held various types of narrative (Cense, 2014), biographic (Cense, 2015) and in-depth interviews (Cense \& Ganzevoort, 2017) with Dutch youth (varying in age from 12 to 30 years) on their sexual history/biography; their experience and expression of sexual identity and same-sex desires; and their attitudes, motivations, and experiences regarding unwanted sexual behaviors. In some of these studies visual materials were used to support and structure the interview, such as lifeline drawings (Cense, 2014), or identity circles (Cense \& Ganzevoort, 2017). Comparably, O'Sullivan and colleagues (2007) used a card system in an interview setting in which American adolescents (aged 12-21 years) were asked to chronologically order different events (e.i., social, romantic, and sexual), to gain insight into the different types of developmental trajectories of their intimate partner relationships. Luke and colleagues (2011) developed a Relationship History Calendar, based on the life history calendar method, in which questions were asked about the relational and sexual histories of Kenyan young 
adults (aged 18-24 years), in a visual (a schematic calendar), retrospective (the last 10 years), and detailed (from month to month) way.

Explicitly mentioned (and partly tested) benefits of such face-to-face interview methods, in comparison with questionnaire methods, is that they generate a higher willingness to participate and a more complete dataset, reduce socially desirable answering (and therewith also distorted gender differences), and that they are sufficiently valid when the goal is to sketch youth's relational and sexual histories (Luke et al., 2011; Rolnick, Gross, Garrard, \& Gibson, 1989). Different researchers have argued that these benefits outweigh the relatively high costs (time and money) that are typically associated with these in-person interview methods. Moreover, it was found that the relational and sexual history interviews utilizing the Relationship History Calendar method, despite its significantly less acceptable duration, was characterized by significantly more connection between the interviewed youth and the interviewers, as well as a significantly more pleasant experience-for both the interviewers and the participants-compared to interviews utilizing the Sexual Partnership Questionnaire (Luke et al., 2011).

Although the aforementioned interview methods were also partly focused on the retrospective, chronological, and in-depth mapping of the relational and sexual histories of youth, they lacked an explicit and combined focus on: (1) how relational and sexual aspects of intimate relations are intertwined, (2) behaviors as well as experiences (cognitions and emotions), and (3) the dynamic and cumulative interrelatedness of succeeding relationship experiences throughout their relational and sexual developmental trajectories. These additions are a central focus in the newly developed interview method that is described in this paper.

\section{The Relational and Sexual History Interview: How Does It Work?}

The newly developed RSH interview method has, like many of the methods described above, the form and characteristics of a semi-structured in-depth interview (Boeije, 2009 \& Kvale, 2007). Specifically, the developed RSH interview topic list consists of five consecutive steps (see Appendix). The questions were based on similar studies on the relational and sexual development of young adults (De Graaf et al., 2017; Luke et al., 2011) and selected for the purpose of the research questions of the larger young partner study for which this method was developed ("Lovely sex of sexy love?"; Van de Bongardt, 2018). In addition to the topic list, the RSH interview is also supported by a relationshipmatrix (see Fig. 1), in order to visually sketch how the chronological developments in romantic and sexual aspects of intimate relationships of youth are linked and related to one another. This visual helps the interviewee and interviewer to create together a clear, dynamic, summarized, and chronological overview of the relational and sexual history of the interviewee and serves as a valuable tool for conducting the rest of the interview, as well as storage of the collected data. What follows, is a more detailed description of the five steps of the RSH interview method as it was used in the present smallscale, qualitative study in which this method was developed and piloted. ${ }^{1}$

\section{Step 1: Description of the Relationship History}

In the first step, all romantic/sexual relationships were mapped out using the relationship matrix (see Fig. 1; printed on A3-format paper). The interviewer asked the interviewees how many relationships they have had and continued by asking questions about their first relationship. The relationship characteristics were added into the relationship matrix, including the chronological characteristic of the relationship (i.e., duration of the relationship with start- and end-date, and the interviewee's age at the start and end of the relationship), and several partner characteristics (i.e., gender, age, education level, ethno-cultural background). ${ }^{2}$ The other discussed topics at this step were being in love (and the development hereof over time), types of sexual activities and the frequencies hereof, the presence of orgasm for the interviewees and their partners, condom/contraception use and how well they could talk with their partner about their relationship and sexuality. In addition, discrepancies between the interviewee and their partners' prior experiences with relationships and sex were discussed. When there was a discrepancy, it was further discussed whether and how this difference was manifested. At the end of this first step, both the interviewee and the interviewer had a global, visualized overview of the relational and sexual aspects of all relationships, to which they could refer back in the next steps. Step 1 generally took up

\footnotetext{
1 The development of the RSH interview method, and the pilot study to try this method out, have been described in a Dutch publication in the Dutch Journal of Sexology (Van de Bongardt, Verbeek, \& Rook, 2019).

${ }^{2}$ On the one hand, scientific literature shows that socio-demographic characteristics, such as ethno-cultural background and educational level, are related to relational and sexual developmental aspects of young people (De Graaf et al., 2017). On the other hand, the RSH interview method can be used exploratively to provide insight into (beforehand unknown) patterns in one's relational and sexual history. Here, patterns in partner choice and selection may also emerge. Asking about socio-demographic characteristics of the partners may be relevant in this respect, but other partner- or relationship characteristics can also be requested, depending on the scientific research question or the clinical request for help.
} 


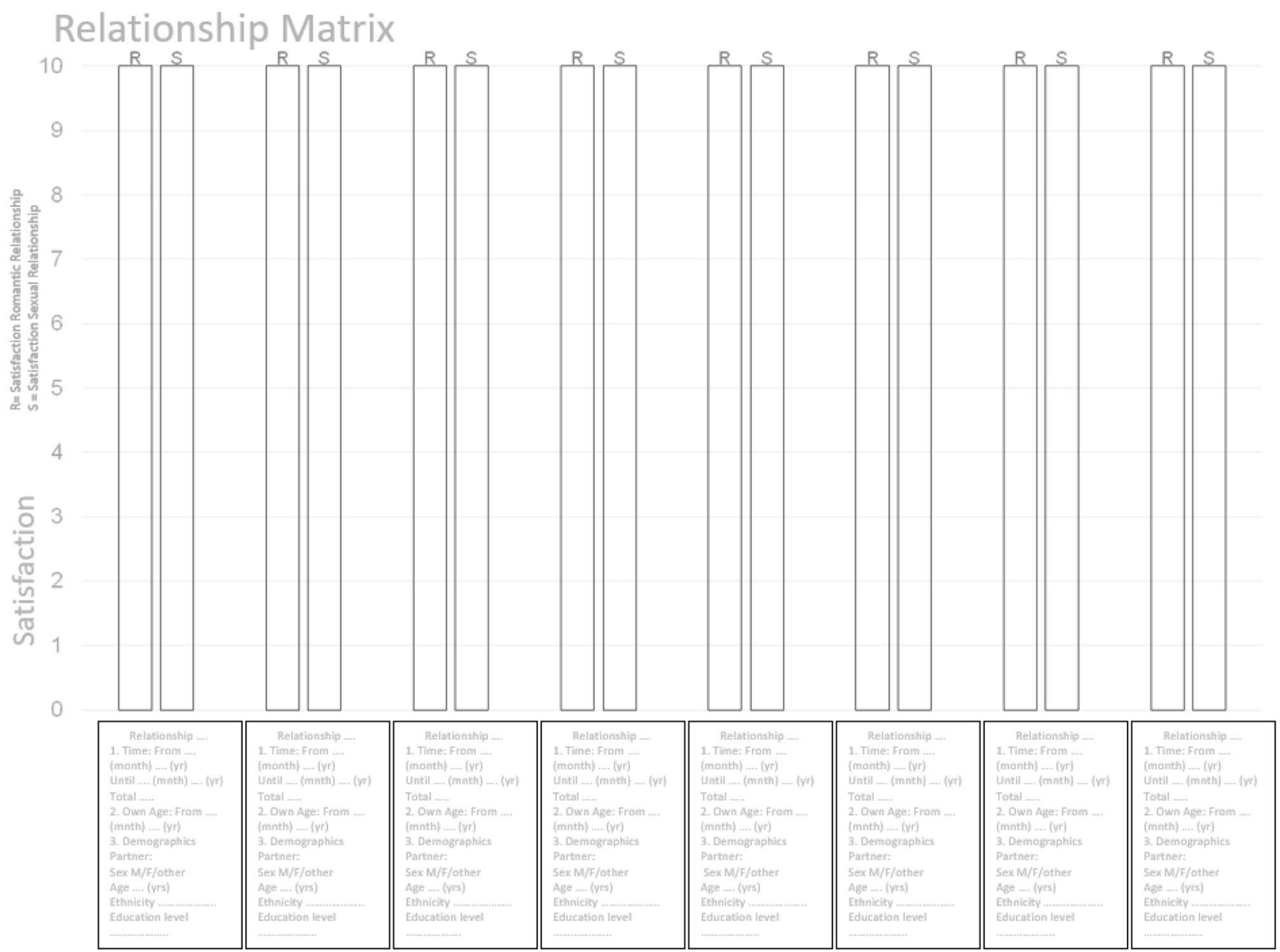

Fig. 1 The relationship matrix that is used to support the Relational and Sexual History Interview

most of the time ( \pm 10 min per relationship), depending of the number of relationships that had to be discussed.

\section{Step 2: Relational and Sexual Satisfaction}

In the second step, the interviewees' satisfaction about all their relationships was added into the relationship matrix. For each relationship, the interviewees rated on a scale from 0 to 10 how satisfied they were (when looking back now) with the romantic aspects, on the one hand, and the sexual aspects, on the other hand. They were subsequently asked to clarify the given score. Here, the interviewees mentioned relationship factors that influenced their satisfaction-score. Finally, in this step, the interviewees were explicitly asked whether they had ever experienced control or pressure from a partner, and whether unpleasant or undesired things had happened regarding sexual and/or relational aspects. The goal was to give the interviewees space to mention and reflect on this.

\section{Step 3: Transitions Between Relationships}

To sketch the dynamic character of the relational and sexual histories of the interviewees, in Step 3, the emphasis lay on the transitions between the different relationships. First, questions were asked about the factual descriptions of the relationship transitions, such as how much time there was between the relationships, how each relationship had ended, and how the next relationships had started. After this, the interviewees were asked to think about the positive and negative relational and sexual aspects of each relationship, and to what extent these aspects were brought from the previous relationship into the new relationship. This could be aspects they liked about the relationship and would like to have again, or things they disliked and did not want to experience again. Based on their answers, elaborating questions were asked, to get more in-depth insight into whether they had succeeded to take the positive aspects with them into their 
next relationship, but not the negative things, and why they had managed to do so or not.

\section{Step 4: Holistic Integration of Relationships-I}

During the fourth step, the interviewer zoomed out further onto the whole relationship matrix and focused on the total relational and sexual history of the interviewee. Here, the interviewees were encouraged to reflect on the question from which relationship they had learned most in terms of the positive relational aspects of an intimate relationship (i.e., aspects they liked), and from which relationship they had learned most in terms of the negative relational aspects (i.e., aspects they did not want again). The same was asked regarding positive and negative sexual aspects.

\section{Step 5: Holistic Integration of Relationships-II}

In the fifth and final step of the RSH interview, the interviewees were asked again to look back onto their full relationship history, and to think about how pleasant or unpleasant their intimate relationships had been, and to indicate to what degree this overall evaluation was due to themselves, due to their partners, or due to the match between themselves and their partners.

As the final part of the fifth step, participants were asked about their own perspectives on the interrelatedness between love and sexuality: "Do you think that the relational aspects of your partner relationship affect the sexual aspects; in other words: when the relationship goes well, the sex goes well (we call this 'lovely sex')? Or do you think that the sexual aspects of your partner relationship affect the relational aspects; in other words: when the sex goes well, the relationship goes well (we call this 'sexy love')? Or both?" For their answer, they were asked to also zoom in on their current partner relationship when relevant, and to elaborate on their choice (e.g., by giving examples). ${ }^{3}$

\section{The Relational and Sexual History Interview: What Kind of Information Does It Yield?}

After the development phase, the new RSH interview method was tried out in a small-scale qualitative study with $N=16$ young adults (nine women, seven men) between 19 and 25 years old $(M=23.0$ years, $S D=2.0)$. Nine of the 16 participants were in a romantic relationship at the time of their participation in the study. Eleven participants

\footnotetext{
${ }^{3}$ Because the data that were collected in this final part of the RSH interviews are currently being analyzed for another paper, elaborating on this step falls outside of the scope of the current paper.
}

identified as a "100\% heterosexual," two as "predominantly heterosexual, but somewhat attracted to individuals of the same sex," two as "predominantly homosexual but somewhat attracted to individuals of the other sex," and one as "pansexual." Thirteen participants had a Dutch ethno-cultural background, and three a non-Western ethnocultural background (i.e., Indonesian, Malaysian, and Brazilian). At the time of the study, two participants were enrolled as a student in higher vocational education, and eight studied at a University. Five participants had graduated from University, and one participant had graduated from middle vocational education. Twelve participants lived independently (i.e., in student housing or their own rental house), one was a homeowner, and three lived with their parents. The number of relationships the participants reported about in the RSH interviews varied between two and eight (median $=$ four relationships). The duration of the relationships varied between 2 weeks and 7.5 years ( $M=16.5$ months). Out of the total of 59 documented relationships when relevant, the majority was heterosexual (other-sex partnerships), and two relationships were homosexual (same-sex partnerships).

\section{Procedure}

After ethical evaluation and approval (see Acknowledgements), participants were recruited at tertiary education institutes (middle and higher vocational education institutes and universities) with face-to-face approaches on campus, posters, and flyers; via social media (Facebook, Instagram, LinkedIn), and through personal networks of research assistants. To be eligible for participation, one had to be between 18 and 25 years old and had to have been engaged in a minimum of two heterosexual relationships that were romantic as well as sexual in nature. The second criterion was included because of the nature and goals of the RSH interview, as it was developed in the present study, but is not a prerequisite for the use of this interview method, nor is the age range.

The interviewees participated after being fully informed about the study, and on a fully voluntary basis. Prior to the interview they received an information letter that explained the study, the goal, the procedure, confidentiality of the collected data, the voluntariness and possibility to receive more information. A consent form was signed to confirm that participants had read and understood all the information in the letter and agreed to participate in the research. At the start of the interview, the interviewers emphasized again that all data obtained was confidential, and that participants could stop the interview or end their participation in the study at any time and without giving an explanation. After the interview, each participant received a small incentive (a $€ 20$ gift voucher) as was announced during recruitment. 


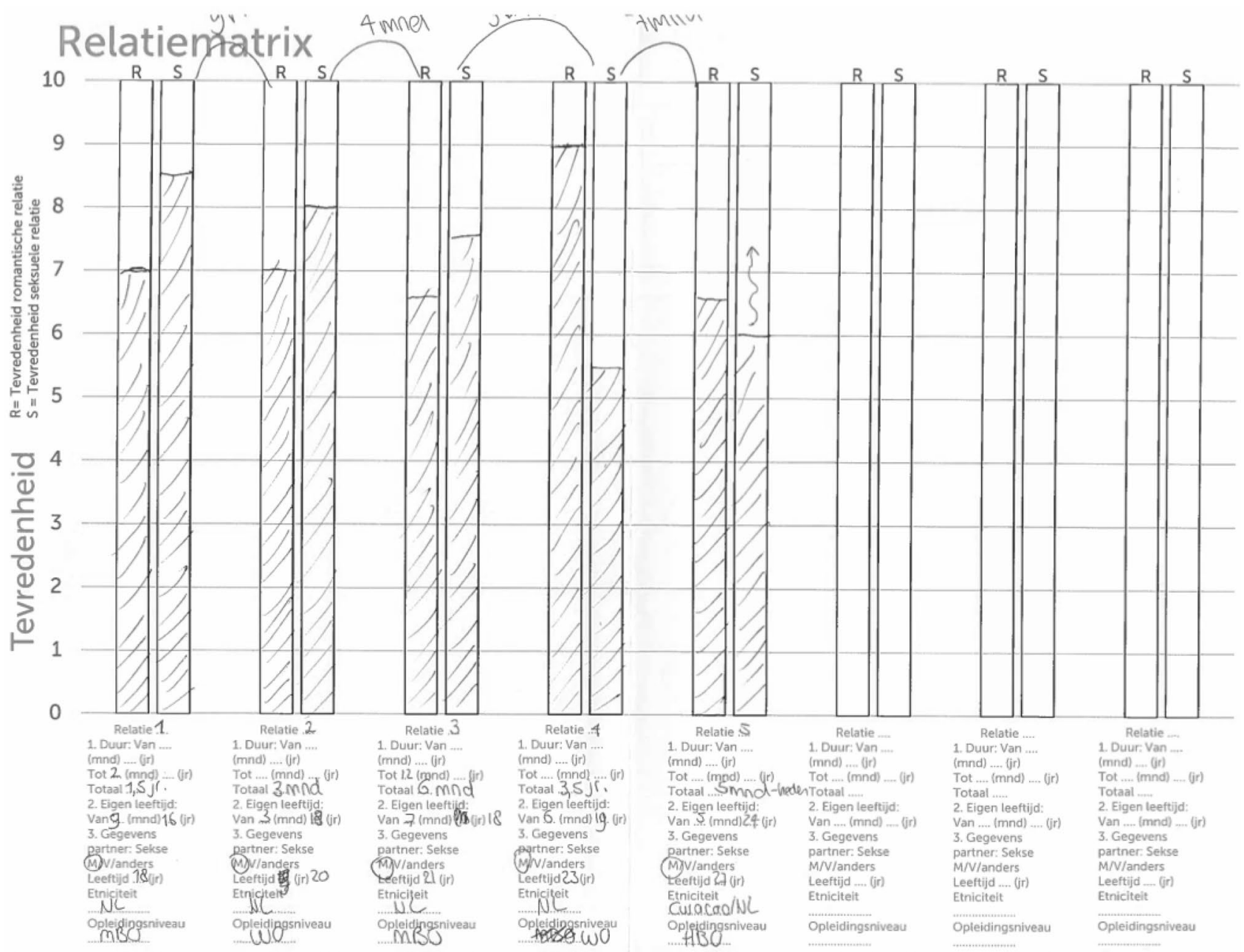

Fig. 2 Example of an analogous (raw) filled in relationship matrix after one of the RSH interviews (in Dutch).

After a multi-day training of the research assistants (with educational backgrounds in developmental psychology,(ortho) pedagogical sciences, and/or sexology), four pilot interviews were held with participants who had signed up for the study, but did not fully fit the inclusion criteria (e.g., because they were older than 25 years). Based on these pilot interviews, several small adjustments were made to the topic list. After this, the semi-structured in-depth interviews were held individually and face-toface with the 16 interviewees, at locations that the participants preferred (e.g., at a university, or at their home). At all locations, privacy was guaranteed because no other people were present, and the interviewees could speak freely. All interviews were recorded with digital audio recorders, and the recordings were fully transcribed verbatim. The length of the interviews varied between \pm 25 and 120 minutes, which largely depended on the number of intimate relationships that were part of the participants' relational and sexual history.

\section{Results}

What follows is not a thick description of the analyzed results from the pilot study, but rather an illustration of the type of information that the developed RSH interview method may generate.

\section{Step 1: Describing the Relational and Sexual Partners and Experiences}

Figure 2 displays a completed relationship matrix from one of the interviews. Next to the heterosexual character of most of the relationships of the interviewed young adults, their relational histories consisted mostly of serial monogamous relationships, whereas two of them were described as an open relationship. The interviewees differed between 0 to 11 years in age with their partners and were on average 1.2 years younger than their partners. However, when considering men and women separately, women were on average 2.4 years 
younger than their (mainly male) partners, and men were on average 0.4 years older than their (mainly female) partners.

The interviewees indicated that in most relationships they had been very much in love at the start of the relationship. These initial infatuations usually developed in three ways: (1) the interviewee quickly felt less in love, (2) the feeling of being in love only grew stronger, usually on both partners' sides, and (3) the feeling of being in love remained continuously and strongly present until the end of the relationship (until the last weeks or months). In some cases, the partner of the interviewee initiated the relationship, while the interviewee was not in love, or the relationship started because of other reasons than being in love, like "wanting to feel included" or "a rebound" (i.e., a relationship right after a previous relationship has ended, because the interviewee did not want to be alone).

In response to the questions about the factual descriptions of the relationships-such as the ages, types of sexual activities, and the use of contraception-the interviewees often elaborated about the development of their relational and sexual history. Especially the questions on how well they could talk with their partners about their relationship and sexuality provided insight in the development of the relationships, and the interviewee's experience thereof. Through this step, the interviewers got a first, elaborate insight into the interviewees' different relationships and partners.

\section{Step 2: Satisfaction with Romantic and Sexual Aspects}

In Fig. 3, the relational and sexual satisfaction scores of all interviewees $(N=16)$ are displayed. The diagrams show the inter- and intra-individual variations in the relational and sexual satisfaction scores of the interviewed young adults.

Relational Satisfaction. The satisfaction scores for relational aspects varied from 1.0 to $9.5(M=6.8, S D=0.9)$, see Fig. 3. Often, the given rating was the result of a consideration of the most positive and most negative aspects, or an averaging of how the relationship was at the beginning and how it ended:

[...] look, if I would solely have to describe how it was between us, maybe a bit higher, but it just did not go well because of how we felt about it (...) And also slightly because of the people around us who kept asking: what are you, what are you? So that, yeah, that just did not work. (Male interviewee, 23 years)

He was truly so handsome, like wow. Every time I saw him, I thought 'how can you be with me?' Really like that, and very strongly. But so that aspect was really, that was much stronger than with [name partner \#1] that I really [thought] 'WOW'. But, yeah, could we really talk to each other? Well, no not really, actually. Because he was really a total loner and he only wanted this, so that actually did not work at all. So, then it would come down to a 7, because I really was very much in love. (Female interviewee, 24 years)

Low satisfaction scores (under 5.5) were mainly motivated by the fact that the interviewees themselves were not (yet) in love with their partners. Average scores (5.5-7.5) where often given when some aspects were rated as positive and simultaneously other aspects were rated as negative. This was for instance observed with one of the female interviewees:

Because I just really feel that he is very confused, with the pushing and pulling. And I know that he really likes me a lot, and I also like him a lot, but because of this I don't always get, I only get to a 10 , so to say, at the moments when he is not pushing me away. Then it is truly fantastic, and then he can lie next to me, and then I get to an 11, so to say. But when he is in that mood like 'stop', then I really get to a 3. (Female interviewee, 24 years)

High scores (7.5-10) were mainly substantiated by the interviewees by the presence of strong feelings of being love, being a good match and having good communication. Often the first relationship was rated relatively highly on relational aspects, because it was "new" and "the first real relationship." With high scores the interviewees more often used superlatives (for instance "super in love"), and more often mentioned special relational aspects (e.g., "we had the same goal," "we have managed to stay together for a really long time," "we have been able to get through a hard time together").

Sexual Satisfaction. The interviewees scored the sexual aspects of their relationships from 2.0 to 10.0 $(M=7.4, S D=1.5)$, see Fig. 3. Low scores were usually substantiated by not experiencing much attraction, not being in love, having an inexperienced partner, or the sex did not feel nice or not feeling comfortable during sex. One male interviewee's explanation for his low sexual satisfaction score was that his partner could not achieve an orgasm. One female interviewee's explanation was experiencing a lot of pain during sex. Also for the sexual aspects, interviewees often gave an average grade when some aspects were satisfying, but others not so much, for instance when they were satisfied about how well they were attuned to one another and how attractive they thought their partner was, but at the same time less satisfied about how their partner handled STI prevention. With higher scores, interviewees for instance said that the sex was very nice, partners were well-attuned to each other, the sex was carefree, and there was space to be open and try new things. 


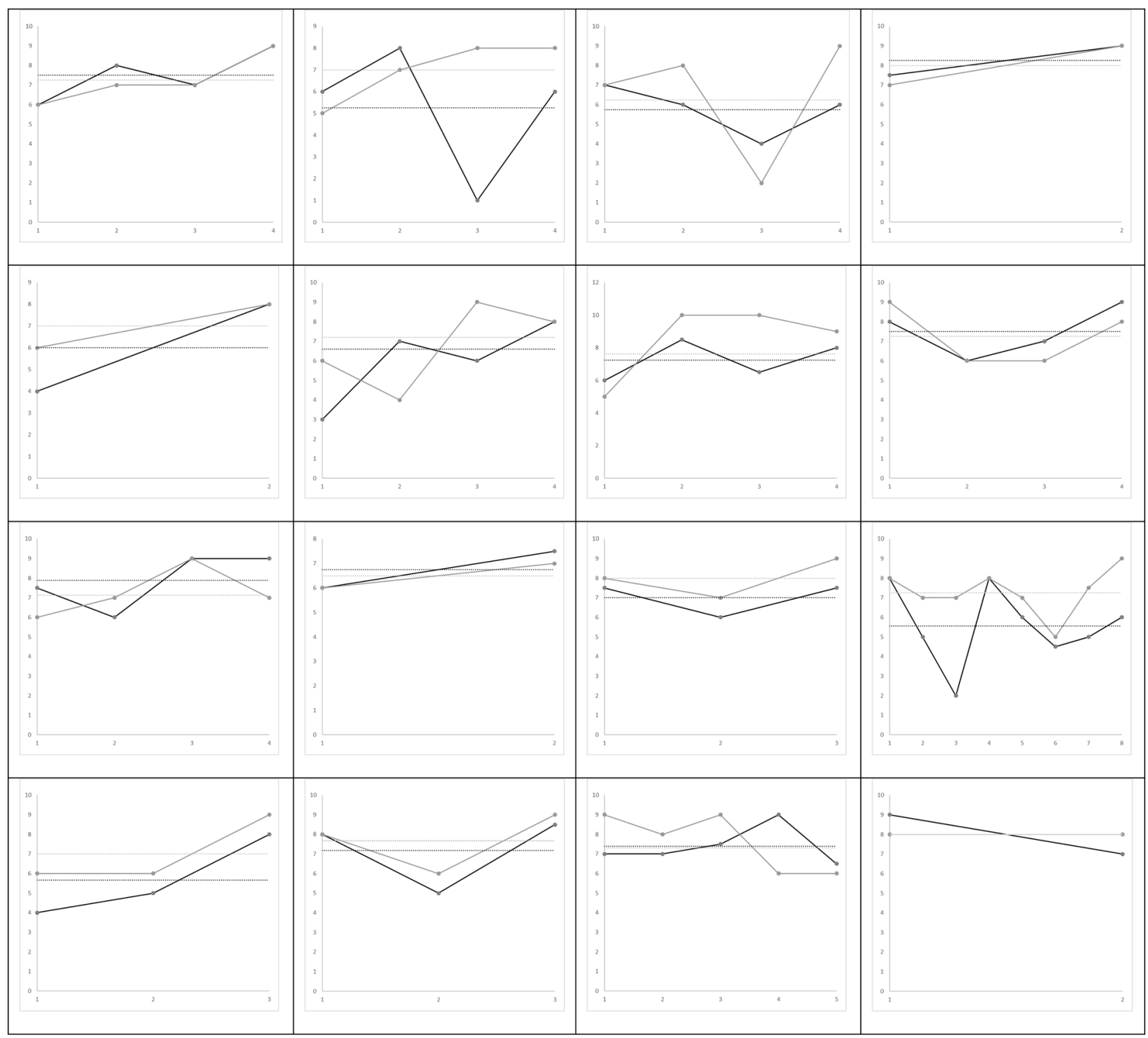

Fig. 3 Diagrams of the inter- and intra-individual variations in relational and sexual satisfaction scores of the interviewed young adults $(N=16)$. The black and gray solid lines represent the relational and sexual satisfaction scores ( $Y$-axis), respectively, for each relationship

Difference in Relational and Sexual Satisfaction. Although caution is necessary when interpreting quantitative data based on a sample of 16 young adults, Fig. 3 shows that the interviewees were on average somewhat more satisfied about the sexual aspects of their relationships $(M=7.4)$ then about the relational aspects $(M=6.8)$. In addition, different individual patterns were revealed in the interaction between sexual and relational experiences. Out of the 16 interviewees, seven of them consistently showed higher sexual than relational satisfaction across all their relationships, two consistently showed higher relational than sexual satisfaction, one had similar relational and sexual satisfaction scores chronologically ( $X$-axis). The black and grey dotted lines indicate the mean scores on relational and sexual satisfaction, respectively, of each interviewee across all their relationships (min. 2-max. 8).

across relationships, and six interviewees showed a mixed satisfaction pattern (i.e., they were equally often more satisfied with the sexual aspects as they were with the relational aspects, or equally satisfied with both aspects).

The added value of visualizing these variances between and within persons-also in a relatively small sample of 16 young adults-encompasses two aspects. Firstly, it shows that global questioning on relational or sexual satisfaction at an individual level (for instance combined for all relationships at once, i.e., "life-time") is potentially insufficient for some objectives, because this can strongly vary in each relationship. Secondly, the amount of intra-individual variance 
in relational or sexual satisfaction in and of itself can be informative to map out and understand the relational and sexual history of an individual and patterns therein. This assumption (i.e., the meaningfulness of intra-individual variability) also forms at the base of all methods of diary and experience sampling studies (e.g., Bolger \& Laurenceau, 2013).

\section{Step 3: Relationship Transitions}

Step 3 mainly yielded information about relationship-transitions: How the interviewees met their partners, how and why their relationships ended, and how much time there was between subsequent relationships. A part of this information often already presents itself in Step 1 during the description of the chronological order of the relationships, and can in that case be skipped, or just shortly confirmed in this step.

Of all relationships discussed, for 44 relationships it was mentioned how they had begun. Most relationship had started after meeting each other during nightlife/in a bar/at a party ( $n=8$ relationships), via another person both partners knew ( $n=7$ relationships), via dating apps ( $n=7$ relationships), or the relationship started as a friendship ( $n=5$ relationships). Some relationship had started after meeting at a student association ( $n=3$ relationships), as roommates ( $n=2$ relationships), at work ( $n=2$ relationships), or during introduction days of their study ( $n=1$ relationship).

The broken-up relationships had mostly been ended by the interviewees themselves ( $n=28$ relationships), in a few cases by their partner ( $n=6$ relationships), and in some cases by both partners together ( $n=3$ relationships). There was a large variation in the mentioned reasons for ending the relationships. These can be classified into cognitive, behavioral and emotional motives.

Firstly, there were cognitive motives - connected to cognitive experiences of the relationship - to end relationships, such as having doubts about the relationship, experiencing different life phases, a partner or relationship that did not meet expectations, not wanting a serious relationship, experiencing distance between partners, differences in expectations regarding investment in the relationship, dissatisfaction about frequency of contact, boredom, or the type of relationship that was not satisfactory.

Secondly, behavioral motives to end the relationship were mentioned, connected to the interviewees' own behavior or that of the partner, including: infidelity or cheating by the partner or the interviewee, a partner who was controlling or the interviewees themselves being controlling toward the partner, infrequent or low-quality communication (in general or about feelings), noticing that distraction was sought, experiencing a lot of conflict, a partner who did not invest much into the relationship, or manipulative behavior of the partner.
Thirdly, there were emotional motives-connected to emotional experiences of the relationship - to end the relationship, for instance: feelings of being in love that had decreased or disappeared, being scared to acknowledge feelings, feelings of being in love did not develop to loving the other person, irritations or anger between partners, the partner also having feelings for someone else, or the emotional connection that had disappeared.

Other reasons why a relationship ended were that the partner needed more space, wanting to be the one to end it, distance, traveling or migrating to another country, interference from outside the relationship, or meeting the next relationship partner.

It is noteworthy that most of the mentioned motives to end a relationship had a relational nature (e.g., had to do with the relational dissatisfactions). Any type of sexual dissatisfaction was not mentioned by any of the interviewees as a reason to end the relationship.

Across all interviews, there were no uniform patterns in how much time there was between subsequent relationships. The intervals ranged from a few months to a couple of years. The longest period between relationships that came up was a period of three years. The lack of a time interval between two relationships (i.e., in the form of relationship overlap) only happened several times: four interviewees had experienced an overlap between relationships one time, and one interviewee had experienced an overlap between relationships two times.

\section{Step 4: Evaluation of the Most Insightful Relationship}

Although interviewees had often already indicated at Steps 2 and 3 what they experienced as positive and negatives aspects of their relationships, and what aspects they did and did not wanted to take along into a next relationship, these comparisons were explored more in-depth in Step 4. A few interviewees explicitly referred to their answers given in Steps 2 and 3. For instance, some interviewees had already discussed what they thought was positive or negative about their relationships in Step 2, as a substantiation for their satisfaction-scores, so in Step 4 they sometimes referred back to that step. Interviewees discussed their relationships in Step 4 in four combined ways: positive and negative romantic and sexual aspects. From this, a general picture emerged regarding from which relationship the interviewees had learned the most.

Most Insightful Relationships. The interviews showed that most interviewees had learned the most from their longest relationship (regarding positive aspects: $n=8$, and negative aspects: $n=4)$. In addition, interviewees indicated that they learned most from the first and second relationship, both for positive aspects (first relationship $n=5$, second 
relationship $n=4$ ), as well as for negative aspects (first relationship $n=5$, second relationship $n=6$ ). For some interviewees, the first or second relationship was also their longest relationship.

Insightful Relational Aspects. In response to the question what the interviewees had learned the most in terms of positive relational aspects, they answered the following: trust, putting in effort for each other, being thoughtful toward each other, being able to lean on each other, being allowed to show emotions, organizing fun things for the other person, doing fun things together, giving each other freedom, and having a partner who can give you insights.

In terms of negative relational aspects of a relationship, the balance between dependence and independence was mentioned as the most valuable lesson learned from a relationship. Both being too dependent and being too independent were discussed here. Interviewees also noted that staying in a relationship despite not having feelings for that person was what they learned most about what they did not want in a next relationship. In this respect, it could be related to feelings that had dissolved during the relationship or feelings that were absent from the start. Also mentioned as answers to the question what they had learned most in their relationships in respect to what they did not want, were: dishonesty, inequality, no (good) communication, and having different interests.

Insightful Sexual Aspects. In response to the question what the interviewees had learned the most with regard to positive sexual aspects, they answered: gaining (a lot of) experience, learning what feels good and what does not (both for themselves and for the another person), that pleasure is important for both partners, communication about sexuality, having the space to experiment, seeing sexual contact as something fun and as something that should not be taken too seriously, and variation in sexual activities.

Regarding negative sexual aspects that they did not want in future relationships, the interviewees listed: continuing sexual contact while it hurts or while they actually were not in the mood for it, having "conservative sex" (i.e., always the same position and limited variety), not talking about sexuality, not experiencing fun and/or pleasure from sexual contact, and not sensing each other's sexual needs.

\section{Step 5: Role of Match, Partner, or Self}

In the last step, the question was asked to what extent the experience of the relationships was related to the interviewees themselves, their partners, or the match between the two. Some answered that it was mostly because of themselves, for instance because they were not able to commit, or were not yet serious enough. Some interviewees easily answered this question for all their relationships at once, while others answered it for each relationship separately because they saw differences across their relationships in terms of their own role, their partner's role, or that of their match playing the biggest part. Nevertheless, many interviewees eventually named the importance of the match, because this eventually led to the individual roles of the partner and themselves. Sometimes an answer gave insight into a combination of the role of the interviewees themselves, their partners, and the match, which illustrates the possible interwovenness of these three aspects:

Yes, I believe that everything comes from two sides [match], but that I was also perhaps a bit unfortunate in the type of boys they were [partners]. Because, I know that I really had an ideal picture [self]. From relationship 2, yes actually after that whole incident, so to say, I really had an ideal image of boys, and they had to live up to that, and if this was not the case then I usually said something about it. Well I did not say 'you do not live up to my ideal picture', but I did say 'why do you do this, why can you not just act sweet' or whatever. And then I very often ended up having an argument about it [match]. (Female interviewee, 19 years)

\section{Experiences of the Interviewees}

The feedback about the RSH interview method that we received back from the interviewees was over all positive. Most of them enjoyed being interviewed about these subjects, found it interesting to map their own relationship history using this method, and indicated that it changed their way of thinking about this. Several interviewees said that it was comfortable for them that the interview was conducted by an interviewer of their own age, but this is of course not a strict condition for using the RSH interview method.

\section{Clinical Applicability}

Although the RSH interview method was developed for research purposes, it can also be used in clinical practice. To illustrate the clinical applicability of the developed RSH interview method, it was used in a clinical case by one of the involved research assistants who was also working as a sexologist. It concerned a man in his early thirties who, according to himself, got stuck in his sexual thoughts, fantasies, and behaviors. He experienced shame in talking about (his) sexuality. To help him get a better understanding of himself, the first four steps of the RSH interview were used. For instance, questions were asked about being in love and the sexual experiences in his earlier relationships, the communication between partners about the relationship and sexuality, and how the client felt about this (i.e., his satisfaction about this communication). Next to this, he was asked what 
he had learned from his relationships, and to what extent he managed to take what he had learned, and his wishes and boundaries into a new relationship.

The method offered a clear guideline to ask about the client's relational and sexual history. The manner of asking questions (i.e., to ask in a chronological order about certain aspects per relationship) helped to make certain behavioral patterns visible, and to form a complete view of his relational and sexual experiences and the interconnectedness between the two. The interview helped the client to get more insight into his own relational and sexual development. He recognized that partners with whom he did not feel safe, either due to himself or his partner, contributed to his fear and reluctance to open up about his sexual fantasies. The RSH method was further applied to ask about his upbringing situation (e.g., how his family had dealt with sexuality at home, and what messages and values about sexuality he had received from his parents) and the interaction of this with his relational and sexual development. By mapping his history in this way, explanations and solutions could be found for his request for help. He was, for instance, able to improve his understanding of why he was scared and reluctant to be open toward his current partner about his sexual preferences.

\section{Discussion}

In this paper, we have described the development and pilot of a new interview method that provides the opportunity to sketch the dynamic association between early experiences with romantic relationships and sexuality of youth in a structural, qualitative, retrospective way and with specific attention for intra-individual developments, transitions between relationships, and individuals' own cumulative experiences. The newly developed semi-structured interview method, the RSH interview, enables enhanced insight into how developments in romantic and sexual aspects of early intimate relationships are interlinked. It does so through an explicit and combined focus on: (1) how relational and sexual aspects of intimate relations are intertwined, (2) behaviors as well as experiences (cognitions and emotions), and (3) the dynamic and cumulative interrelatedness of succeeding relationship experiences throughout their relational and sexual developmental trajectories. In five steps, the RSH interview provides information about: the chronological relationship history, including the characteristics of these various relationships (Step 1), the satisfaction (including substantiation) about these relationships regarding relational and sexual aspects (Step 2), the transitions between the relationships (Step 3), the positive and negative aspects that were learned from these relationships, both in terms of relational and sexual aspects (Step 4), and a reflection on the role of the interviewee him-/herself, their partners, or the dynamics between the partners (match) in the positive or negative overall evaluation of one's relationship history (Step 5).

\section{Usability of the RSH Interview Method and the Information It Provides}

As described, the RSH interview provides a multifaceted and unique combination of research data that can be used aggregated across different subjects, as well as individually to gain insight into the chronological, dynamic, and intertwined relational and sexual history of young adults. There are numerous possible adaptations for the developed RSH interview method. Although the method has been specifically developed for interrogating a series of (at least two) intimate relationships, the method could also be used for only one relationship; the questions in Step 1 and Step 2, for instance, are well suited for this purpose. Moreover, these steps could also be used to interrogate and map a person's current relationship in a structured way.

In addition, this method can be used not only to discuss intimate relationships that were both romantic and sexual in nature, but also non-romantic sexual partners (e.g., casual sexual partnerships) or non-sexual romantic partners (e.g., a-sexual relationships). Some of the participants of the present study indicated, for example, that they had also learned from their casual sexual contacts about what they did or did not want sexually. Related to this, research findings showing that romantic and casual partnerships may be linked with different socio-sexual competences (e.g., significant differences in the frequency of partner communication about sex) are relevant (Van de Bongardt \& De Graaf, 2020). The semi-structured character of the RSH interview allows to explicitly ask about such contacts as well.

The RSH interview method also offers the possibility to discuss negative experiences more elaborately, for example when the focus lies more on unwanted sexual experiences, sexual or dating violence, or sexual trauma, or to zoom in on positive aspects, such as the development of sexual pleasure over the course of different intimate relationships. Additionally, the RSH interview method provides the opportunity to focus on specific target groups, such as heterosexual, same sex attracted, bisexual, or transgender individuals, or individuals with different cultural backgrounds. In all cases, the entire RSH interview (or when desired in an adapted form), or parts of it, can be used in research, depending on the type of information one would like to collect.

\section{Scientific Applicability}

The RSH interview method is a valuable addition to scientific research as well as clinical practice, because both areas need more attention for knowledge about and insight into the interrelatedness between love and sex, and how the 
development of both domains is intertwined. The RSH interview method was developed as a part of a larger study on the interrelatedness of love and sex within young couples ("Lovely sex or sexy love?"; Van de Bongardt, 2018), and can also be used by other researchers who want to contribute to the expansion of the scientific study of the links between love and sexuality, and-more specifically-the dynamic associations between early experiences with romantic relationships and sexuality of youth. The visualization (description) of these patterns in relational and sexual experienceseither at an individual level (common in clinical settings), or at a group level (applicable in research)—offers a stepping stone toward the exploration of possible factors that lie at the base of relational as well as sexual (dis)satisfactions (explanation). Scientific research shows, for instance, that there are significant relations between (changes in) sexual satisfaction (linked to sexual communications, sexual skills, frequency of sex, number of sexual partners, safe sex, substance abuse) and relational satisfaction (linked to love, devotion, attachment, emotional sensitivity, and relationship stability; Auslander et al., 2007; Davis et al., 2006; Sprecher, 2002; Zimmer-Gembeck, See, \& O'Sullivan, 2015).

Besides the substantive information that can be yielded with this method, it is also possible to study the way in which topics are being discussed during the RSH interview, for instance with a discourse analysis. This way, one could, for instance, uncover scripts about intimacy, romantic relationships, and sexuality (Simon \& Gagnon, 1986).

The RSH interview method can also serve as a valuable addition in research that uses a dynamic systems approach (Kunnen, 2012) to understand young people's relational and sexual development. The explicit attention for intra-individual developments, transitions between relationships, and individuals' cumulative experiences is particularly suitable for uncovering (often non-linear) changes and transitions in young people's relational and sexual development, and the multiple pathways (e.g., differing in the timing, pace, and sequence) in these trajectories (Van de Bongardt, 2019).

\section{Clinical Applicability}

The developed method can also be applied in clinical settings. For instance, the method can serve as a valuable tool for intake interviews in sexology or relationship therapy. It can also help clients to improve their understanding of themselves in these areas, and in some cases, having insight into a client's relational and sexual history is even crucial for the development of an effective treatment plan. The RSH interview method lends itself well to visualize and create a better understanding of the intimate relationship patterns and developing sexuality of clients, for instance regarding certain partner choices, or why relationships are ended (regularly or in a problematic way). This method can also be embedded in a broader interrogation about the life history of clients (e.g., in combination with upbringing or relationships with peers). Here, too, it is possible to apply the whole RSH interview (when preferred, in an adjusted form), or certain parts of it for treatments in sexology or relationship therapy. The RSH interview method can also be combined with principles of Motivational Interviewing (MI), by integrating it with the process of formulating an improvement plan toward healthy and pleasurable intimate relationships and sexuality of young adults (Bahner and Stenqvist, 2020). Furthermore, using the RSH interview method can increase cross-pollination between these clinical fields, by paying more attention to relational context of sexological problems, and by paying more attention to the role of sexuality in (causing or solving) relationship problems.

\section{Limitations and Follow-up}

The described RSH interview method was developed and tried out with a non-representative sample, consisting of highly educated young adults, with mainly Dutch ethnocultural backgrounds, and mainly heterosexual intimate relationship experiences. Follow-up studies should examine what adjustments may be necessary for the usage of this method with youth with a non-Western ethno-cultural background (e.g., Cense, 2014; Cense \& Ganzevoort, 2017), from lower education levels, with cognitive or mental disabilities, or homosexual/lesbian/bisexual youth (e.g., Cense \& Ganzevoort, 2017), and in what form this method can be used for target groups of different ages (younger adolescents or older adults). Also, the RSH interview method was developed to collect retrospective data, by asking participants about their experiences in the past. However, it could also be used in a prospective research design. In an example of such a design, Thomson and Holland (2003) followed a sample of \pm 100 British youth for nine years in a longitudinal qualitative study, and interviewed them multiple times about their development. While such an approach is labor intensive-both for the researchers and for the participants-it limits the risks of memory bias because experiences are questioned more in real time instead of retrospectively. This way, it possibly yields more reliable data on the incremental development of experiences with intimate relationships, the complex dynamic associations between early experiences with romantic relationships and sexuality of youth, and their associated cumulative experiences.

\section{Conclusions and Policy Implications}

All in all, the newly developed Relational and Sexual History interview method may advance scientific research on the linkages between love and sex by providing a way to get more insight into the retrospective and chronological 
relational and sexual development of young people. In contrast with comparable methods, the RSH method contains an explicit focus on (1) the interrelatedness of relational and sexual aspect of intimate relationships (e.g., the relational context of sexual decisions and interactions), (2) behavioral as well as cognitive and emotional experiences (e.g., relational and sexual satisfaction), and (3) the dynamic and cumulative interrelatedness of successive intimate experiences (e.g., how individuals learn what they do and do not want it their intimate relationships). While the method can be relatively intensive, the RSH interview method-just like the comparable Relationship History Calendar method (Luke et al., 2011)—was experienced by the interviewers and the interviewed young adults as fun, interesting, and comfortable. The method (topic list and relationship matrix) can be adjusted in congruence with various scientific and clinical goals and can thus also be a valuable tool for clinical practice in sexology and relationship therapy and increase cross-pollination between these clinical fields.

The underlying philosophies of this new interview method, as well as the type of knowledge that may be yielded by these interviews, may profoundly impact sexual health policies. Regarding educational policies for sexual health promotion in schools, these insights may promote describing the necessity of focusing on both relational and sexual aspects of young people's intimate experiences (e.g., how decisions to initiate or delay first-time sexual intercourse may be linked to scripts about dating relationship status; Van de Bongardt \& De Graaf, 2020). Regarding public health policies (e.g., protocols for general practitioners, OB-GYNs, and STI clinics), these insights may stimulate articulating the importance of discussing the relational context of young people's sexual functioning and sexual health or risk behaviors (e.g., how scripts about 'romantic trust' may interfere with safe sex practices; Feldstein Ewing \& Bryan, 2015). Overall, paying more attention to the complex relational context of sexual decisions and interactions in parenting, education, and clinical policies and practices can eventually contribute in a meaningful way to a healthy and positive relational and sexual development of youth, and their general wellbeing.

Acknowledgments We want to thank the research assistants for their contributions to the development of this new Relational and Sexual History (RSH) interview method (Chantie Luijten, Xja-Hong Kels Xuan, Britt Rook), the initial description of the methodology development in the first Dutch publication (Britt Rook), and the preparation of the present paper (Mara Kirschner). Finally, we are grateful to all the young adults who have participated in the "Lovely sex or sexy love?" interview study.

Funding This interview study was made possible with a subsidy of the Fund for Stimulation and Development of Sexology (Fonds SOS) of the Dutch Scientific Association for Sexology (NVVS). It served as a pilot study for "Lovely sex or sexy love": A mixed-methods research project on the interrelatedness of love, sexuality, and well-being within young adult romantic partnerships, which was funded with an individual Venischolarship by The Dutch Research Council (NWO) [Dossier number: 016.Veni.185.260].

\section{Compliance with Ethical Standards}

Conflict of Interest The authors declare that they have no conflict of interest.

Ethical Approval The Medical Ethical Testing Committee (METC) of the Erasmus MC (University Medical Center Rotterdam) confirmed that the Medical Research Involving Human Subjects Act (WMO) did not apply to the interview study of "Lovely sex or sexy love" (reference number MEC-2018-096), which was therefore exempt from formal medical-ethical approval under Dutch law. The full research protocol of the "Lovely sex or sexy love" research project was evaluated and approved by the Ethics Review Committee of the Department of Psychology, Education, and Child Studies of Erasmus University Rotterdam (reference number \#19-009).

Informed Consent This was obtained from all participants in the research project (described in the methods section).

Open Access This article is licensed under a Creative Commons Attribution 4.0 International License, which permits use, sharing, adaptation, distribution and reproduction in any medium or format, as long as you give appropriate credit to the original author(s) and the source, provide a link to the Creative Commons licence, and indicate if changes were made. The images or other third party material in this article are included in the article's Creative Commons licence, unless indicated otherwise in a credit line to the material. If material is not included in the article's Creative Commons licence and your intended use is not permitted by statutory regulation or exceeds the permitted use, you will need to obtain permission directly from the copyright holder. To view a copy of this licence, visit http://creativecommons.org/licenses/by/4.0/.

\section{Appendix. Relational and Sexual History Interview topic list}

\section{Step 1}

Map all the intimate relationships of the interviewee/client in chronological order.

- Indicate for each relationship:

Relationship number...

Duration: ..........

Own age: from ... (years old) - until ...(years old)

Characteristics partner:

Gender: M/F/other:

Age: .......... (years old) 
Ethno-cultural background:

Education level:

- Was there a difference in previous experiences between you and this partner (with relationships and/or sex)? For instance: did one of you already have more experience with this than the other person? How did this show?

- What about being in love? Ask in an open way, possible in-depth questions are:

Were you in love, and was this mutual / not mutual?

How much in love were you, and how much in love was the other person?

How did the feelings of being in love develop throughout the relationship?

- What sexual things did you do in this relationship? (you can also let interviewee indicate the numbers)

1 Naked touching or caressing

2 Manual sex

a Fingering or jerking off the other person

b Being fingered or jerked off by the other person

3. Oral sex

a Going down on/giving the other person a blow job

b Got down on/got a blow job from the other person

4. Vaginal penetration

5 Anal penetration

- How many times a week did you have sex on average? .............. Did this frequency change over time?

- How often did your partner experience an orgasm during these sexual activities? (you can use the scale)

- How often did you yourself experience an orgasm during these sexual activities? (you can use the scale)
3 Sometimes (a few times)

4 Often

5 (Almost) always

- Did you use contraceptives?

If yes: what kind (condoms, the pill, other)? And for how long?

How consistent were you (both) in using condoms/ the pill/other? (ask about all types)

How did you experience your conversations/negotiations about this (consistent/inconsistent use of condom/the pill/others)?

Easy/difficult?

Were you on the same page?

Or did you have different opinions?

- How did you experience the transition from (consistent) use of condoms/the pill/other to no (consistent) use of condoms/the pill/other, or the other way around? (ask about all types)

When was this?

Reasons for change?

Easy/Difficult?

Were you on the same page?

Or did you have different opinions?

- How well could you talk to each other

About your relationship?

What you did/did not like, or wanted?

How often did you talk about that?

What did/did not you talk about? Were there any taboos?

What did/did not go well in these conversations? Was there a difference in your visions regarding relationships?

About sexuality?

What you did/did not like, or wanted?
1 Never

2 Rarely 
How often did you talk about that?

What did/did not you talk about? Were there any taboos?

What did/did not go well in these conversations? Was there a difference in your visions regarding sexuality?

\section{Step 2}

Note the satisfaction score of the interviewee for each relationship. Rate each relationship on a scale of 1 to 10 .

- "How satisfied were you with the romantic aspects of this relationship? Rate this on a scale from 1 to $10 . "$

Ask the question in an open way. When necessary, you can explain that it is about the satisfaction regarding the romantic aspects of the relationship, for instance: being in love, love, affection, warmth, support, dynamics, togetherness, partnership, communication, etc. Ask for each score why the interviewee gave this score.

- "How satisfied were you with the sexual aspects of this relationship? Rate this on a scale from 1 to $10 . "$

Ask the question in an open way. When necessary, you can explain that is about the satisfaction regarding the sexual aspects of the relationship, for instance: physical aspects (attraction), the frequency of sexual activities, the types of sexual activities, the quality of the sexual interactions, etc.

Ask for each score why the interviewee gave this score.

- To what extent did you experience control and pressure from the other person in your relationship or during sex?

- Did you experience or do unpleasant/unwanted things (in the relationship or with sex)?

\section{Step 3}

When you look at every relationship transition:

- How much time was there in between each set of subsequent relationships?

- How did the previous relationship end (who ended it and why)?

- How did the next relationship start (how did you know each other, and who took the initiative)?
- What positive aspects (things that you liked and would like to experience again) in your previous relationship did you 'take along' to the next relationship? (ask for each relationship)

What positive romantic aspects of the relationship? What positive sexual aspects of the relationship? To what extent were you/were you not successful in doing so? Why?

- What negative aspects (things that did not like and did not want to experience again) in your previous relationship did you 'take along' to the next relationship? (ask for each relationship)

What negative romantic aspects of the relationship?From which relationship

What negative sexual aspects of the relationship? To what extent were you/were you not successful in doing so? Why?

\section{Step 4}

When you look back at your whole relationship history:

- From which relationship(s) did you learn or take along the most regarding positive aspects (things you find pleasant and important in an intimate relationship)?

From which relationship(s) did you take the positive romantic aspects that you find pleasant and important in an intimate relationship?

From which relationship(s) did you take the positive sexual aspects that you find pleasant and important in an intimate relationship?

- From which relationship(s) did you learn or take along the most regarding negative aspects (things you find unpleasant and do not want in an intimate relationship)?

From which relationship(s) did you take along the negative romantic aspects that you find unpleasant and do not want in an intimate relationship? 
From which relationship(s) did you take along the negative sexual aspects that you find unpleasant and do not want in an intimate relationship?

\section{Step 5}

When you look back at your whole relationship history, and think of how good and pleasant (or not) your intimate relationships were:

- To what extent do you think this is

a) Because of you yourself (your role as a partner)

b) Because of your partner(s)

c) Because of the match between you and your partner(s) and the shared relationship dynamics?

\section{References}

Auslander, B. A., Rosenthal, S. L., Fortenberry, J. D., Biro, F. M., Bernstein, D. I., \& Zimet, G. D. (2007). Predictors of sexual satisfaction in an adolescent and college population. Journal of Pediatric and Adolescent Gynecology, 20, 25-28. https://doi. org/10.1016/j.jpag.2006.10.006

Bahner, J., \& Stenqvist, K. (2020). Motivational interviewing as evidence-based practice? An example from sexual risk reduction interventions targeting adolescents and young adults. Sexuality Research and Social Policy, 17, 301-313. https://doi.org/10.1007/ s13178-019-00388-y

Boeije, H. (2009). Analysis in qualitative research. London, England: Sage Publications.

Boislard, M. A., Van de Bongardt, D., \& Blais, M. (2016). Sexuality (and lack thereof) in adolescence and early adulthood: A review of the literature. Behavioral Sciences [Special issue: Adolescent romantic relationships and sex: Development and behavior], 6, \&nbsp;\&nbsp;https://doi.org/10.3390/bs6010008

Bolger, N., \& Laurenceau, J. (2013). Intensive longitudinal methods: An introduction to diary and experience sampling research. New York: The Guilford Press.

Cense, M. (2014). Sexual discourses and strategies among minority ethnic youth in the Netherlands. Culture, Health and Sexuality, 16, 835-849. https://doi.org/10.1080/13691058.2014.918655

Cense, M. (2015). Different culture, different boundary? Youth and sexual non-consensual behavior [Dutch: Anderecultuur, anderegrens? Jongeren en seksueelgrensoverschrijdendgedrag]. In M. van Aken, W. Beyers, M. Deković, M. Geerarts, H. de Graaf, \& E. Reitz (Eds.), Intimate relationships and sexuality [Dutch: Intiemerelaties en seksualiteit] (pp. 89-95). Houten, the Netherlands: Bohn Stafleu van Loghum.

Cense, M., \& Ganzevoort, R. R. (2017). Navigating identities: Subtle and public agency of bicultural gay youth. Journal of Homosexuality, 64, 654-670. https://doi.org/10.1080/00918369.2016. 1196992

De Graaf, H., Van den Borne, M., Nikkelen, S., Twisk, D., \& Meijer, S. (2017). Sex under the age of 25. Sexual health of Dutch youth in 2017 [Dutch: Seks onder je 25e. Seksuele gezondheid van jongeren in Nederland anno 2017]. Delft, the Netherlands: Uitgeverij Eburon.
Davis, D., Shaver, P. R., Widaman, K. F., Vernon, M. L., Follette, W. C., \& Beitz, K. (2006). "I can't get no satisfaction": Insecure attachment, inhibited sexual communication, and sexual dissatisfaction. Personal Relationships, 13, 465-483. https://doi.org/10. 1111/j.1475-6811.2006.00130.x

Impett, E. A., Muise, A., \& Peragine, D. (2014). Sexuality in the context of relationships. In D. L. Tolman, L. M. Diamond, J. A. Bauermeister, W. H. George, J. G. Pfaus, \& L. M. Ward (Eds.),\&nbsp;APA handbook of sexuality and psychology, Vol. 1 Person-based approaches (pp. 269-315). American Psychological Association.

Feldstein Ewing, S., \& Bryan, A. D. (2015). A question of love and trust? The role of relationship factors in adolescent sexual decision-making. Journal of Developmental and Behavioral Pediatrics, 36, 628-634. https://doi.org/10.1097/DBP. 0000000000000190

Giordano, P. C., Manning, W. D., \& Longmore, M. A. (2010). Affairs of the heart: Qualities of adolescent romantic relationships and sexual behavior. Journal of Research on Adolescence, 20, 9831013. https://doi.org/10.1111/j.1532-7795.2010.00661.x

Jones, M. C., \& Furman, W. (2011). Representations of romantic relationships, romantic experience, and sexual behavior in adolescence. Personal Relationships, 18, 144-164. https://doi.org/10. 1111/j.1475-6811.2010.01291.x

Kunnen, S. E. (Ed.). (2012). A dynamic systems approach to adolescent development. Hove, UK: Psychology Press.

Kvale, S. (2007). Doing Interviews. London, England: Sage Publications.

Lantagne, A., \& Furman, W. (2017). Romantic relationship development: The interplay between age and relationship length.\&nbsp;Developmental Psychology,\&nbsp;53, 1738-1749 https://doi.org/10.1037/dev0000363

Luke, N., Clark, S., \& Zulu, E. M. (2011). The Relationship History Calendar: Improving the scope and quality of data on youth sexual behavior. Demography, 48, 1151-1176. https://doi.org/10.1007/ s13524-011-0051-2

Maas, M. K., \& Lefkowitz, E. S. (2015). Sexual esteem in emerging adulthood: Associations with sexual behavior, contraception use, and romantic relationships. Journal of Sex Research, 52, 795-806. https://doi.org/10.1080/00224499.2014.945112

McElwain, A. D., Kerpelman, J. L., \& Pittman, J. F. (2015). The role of romantic attachment security and dating identity exploration in understanding adolescents' sexual attitudes and cumulative sexual risk-taking. Journal of Adolescence, 39, 70-81. https:// doi.org/10.1016/j.adolescence.2014.12.005

O'Sullivan, L. F., Cheng, M. M., Harris, K. M., \& Brooks-Gunn, J. (2007). I wanna hold your hand: The progression of social, romantic and sexual events in adolescent relationships. Perspectives on Sexual and Reproductive Health, 39, 100-107. https:// doi.org/10.1363/3910007

Pedersen, W., \& Blekesaune, M. (2003). Sexual satisfaction in young adulthood: Cohabitation, committed dating or unattached life? ActaSociologica, 46, 179-193. https://doi.org/10.1177/ 00016993030463001

Rolnick, S. J., Gross, C. R., Garrard, J., \& Gibson, R. W. (1989). A comparison of response rate, data quality, and cost in the collection of data on sexual history and personal behaviors: Mail survey approaches and in-person interview. American Journal of Epidemiology, 129, 1052-1061. https://doi.org/10.1093/ oxfordjournals.aje.a115209

Simon, W., \& Gagnon, J. H. (1986). Sexual scripts: Permanence and change. Archives of Sexual Behavior, 15, 97-120. https://doi. org/10.1007/BF01542219

Smiler, A. P., Ward, L. M., Caruthers, A., \& Merriwether, A. (2005). Pleasure, empowerment, and love: Factors associated with a positive first coitus. Sexuality Research and Social Policy, 2, 41-55. https://doi.org/10.1525/srsp.2005.2.3.41 
Sprecher, S. (2002). Sexual satisfaction in premarital relationships: Associations with satisfaction, love, commitment, and stability. Journal of Sex Research, 39, 190-196. https://doi. org/10.1080/00224490209552141

Thomson, R., \& Holland, J. (2003). Hindsight, foresight and insight: The challenges of longitudinal qualitative research. International Journal of Social Research Methodology: Theory and Practice, 6, 233-244. https://doi.org/10.1080/1364557032000091833

Van de Bongardt, D. (2018). Lovely sex or sexy love? A dynamic and dyadic study on the interrelatedness between youths' romantic and sexual development [Veni research project; NWO grant number: 451-17-016]. Erasmus University Rotterdam. URL: www. 1sslproject.nl

Van de Bongardt, D., Verbeek, M., \& Rook. B. (2019). New interview method for sketching the dynamic relational and sexual history of young adults [Dutch: Nieuwe interviewmethode voor het in kaart brengen van de dynamische relationele en seksuele geschiedenis van jongvolwassenen]. Dutch Journal for Sexology, Special issue: "Sex in connection" [Tijdschrift voor Seksuologie, Themanummer: "Seks in verbinding"], 43, 129-143. URL: https://www. tijdschriftvoorseksuologie.nl/artikelen

Van de Bongardt, D. (2019). Youth's sexual relationships and development: Improving our understanding through a dynamic systems approach. In E. S. Kunnen, N. M. P. de Ruiter, B. F. Jeronimus, \& M. A. E. van der Gaag (Eds.), Psychosocial development in adolescence: Insights from the dynamic systems approach (pp. 160-176). Abingdon, U.K.: Routledge, Taylor \& Francis.
Van de Bongardt, D., \& De Graaf, H. (2020). Youth's socio-sexual competences with romantic and casual sexual partners. Journal of Sex Research, 57, 1166-1174. https://doi.org/10.1080/ 00224499.2020 .1743226

Van de Bongardt, D., Yu, R., Deković, M., \& Meeus, W. H. J. (2015). Romantic relationships and sexuality in adolescence and young adulthood: The role of parents, peers, and partners. European Journal of Developmental Psychology, 12, 497-515. https://doi. org/10.1080/17405629.2015.1068689

Welsh, D. P., Haugen, P. T., Widman, L., Darling, N., \& Grello, C. M. (2005). Kissing is good: A developmental investigation of sexuality in adolescent romantic couples. Sexuality Research and Social Policy, 2, 32-41. https://doi.org/10.1525/srsp.2005.2.4.32

Zimmer-Gembeck, M. J., Siebenbruner, J., \& Collins, W. A. (2004). A prospective study of intraindividual and peer influences on adolescents' heterosexual romantic and sexual behavior. Archives of Sexual Behavior, 33, 381-394. https://doi.org/10.1023/ B:ASEB.0000028891.16654.2c

Zimmer-Gembeck, M. J., See, L., \& O'Sullivan, L. (2015). Young women's satisfaction with sex and romance, and emotional reactions to sex: Associations with sexual entitlement, efficacy, and situational factors. Emerging Adulthood, 3, 113-122. https://doi. org/10.1177/2167696814548060

Publisher's Note Springer Nature remains neutral with regard to jurisdictional claims in published maps and institutional affiliations. 